\title{
Hybrid Microstrip/Slotline Ultra-Wideband Bandpass Filter with a Controllable Notch Band
}

\author{
Xuehui Guan, ${ }^{1}$ Ping Gui, ${ }^{1}$ Tao Xiong, ${ }^{1}$ Baoping Ren, ${ }^{1}$ and Lei $\mathrm{Zhu}^{2}$ \\ ${ }^{1}$ School of Information Engineering, East China Jiaotong University, Nanchang 330013, China \\ ${ }^{2}$ Department of Electrical and Computer Engineering, University of Macau, Taipa 999078, Macau \\ Correspondence should be addressed to Xuehui Guan; sgxh2000@163.com
}

Received 13 March 2017; Revised 1 June 2017; Accepted 2 July 2017; Published 31 July 2017

Academic Editor: Angelo Liseno

Copyright (C) 2017 Xuehui Guan et al. This is an open access article distributed under the Creative Commons Attribution License, which permits unrestricted use, distribution, and reproduction in any medium, provided the original work is properly cited.

An ultra-wideband (UWB) bandpass filter (BPF) with a controllable notch band is presented by using hybrid microstrip/slotline structure. Firstly, a slotline resonator with symmetrically loaded stubs is fed by two microstrip lines to produce a UWB bandpass filtering response. Secondly, a microstrip triangular loop resonator is externally loaded over the slotline, and a notch band is introduced in the UWB passband. The notch band is determined by the perimeter of the loop resonator. Thirdly, two patches are added as the perturbation element to the corners of the microstrip resonator to excite a pair of degenerate modes. Bandwidth of the notch band can be tuned by properly selecting the patch size. Circuit model for the microstrip resonator loaded slotline is given and studied. Finally, the filter is designed, simulated, and measured. Measured results have agreed well with the simulated ones, demonstrating that a UWB filter with a controllable notch band has been realized.

\section{Introduction}

Continuous progress in wireless systems requires advanced $\mathrm{RF} /$ microwave components, like well-designed filters. Ultrawideband (UWB) characteristics are in order to meet the subscribers' demands. Many methods have been proposed to design various UWB bandpass filters (BPFs) by using multimode resonators (MMRs) [1, 2], multilayer steppedimpedance resonators (SIRs) [3], and stub-loaded resonators [4]. To acquire the desired strong coupling between resonator and feed lines while keeping the gap width between striplines in a moderate scale that can be achieved easily by using PCB process, an aperture-backed parallel-coupled microstrip line with enhanced coupling degree is constructed to allocate the coupling peak $[5,6]$. For some practical applications, there is a need to avoid the interference from existing wireless communication systems such as wireless local area network in 5.0 GHz band. Generating a notch band in a UWB BPF is an effective and feasible method to solve this problem. As usual, an external resonator is used to create a notch band in the core of the UWB BPF at the cost of enlarged size [7]. In [8, 9], a SIR is embedded to achieve a band notch characteristic without increasing the circuit size. Band-notched filtering effect was achieved by adding a meander line slot to reject the undesired WLAN radio signal [10]. In [11], two spurline sections are employed to create a sharp notched-band filter for suppressing the signals of $5 \mathrm{GHz}$ WLAN devices. In [12], a dual-mode fractal defected ground structure (DGS) bandstop filter is realized and connected with MMR; band-notched characteristics are realized. To avoid the interference of the wireless local area network (WLAN) at 5.25 and $5.775 \mathrm{GHz}$, two different quarter-wavelength lines are arranged on the ground of UWB BPF to generate dual narrow stop band [13]. Obviously, combined bottom layer and top layer can make full use of the circuit board, without increasing the circuit size [14].

In this article, a hybrid microstrip/slotline structure is adopted to develop a novel UWB BPF with a controllable notch band. UWB bandpass characteristics have been achieved by using a microstrip-fed multimode slotline resonator. Desired strong coupling is simply realized by changing the position between microstrip and slotline portions. When a microstrip dual-mode triangular loop resonator is loaded to the slotline, a notch band is created in the UWB passband. Circuit model for this structure is provided and 


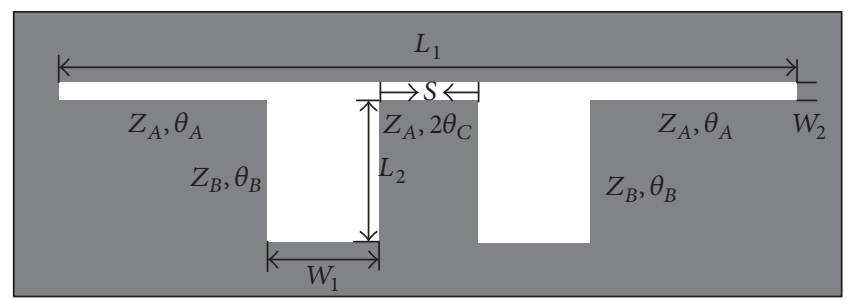

(a)

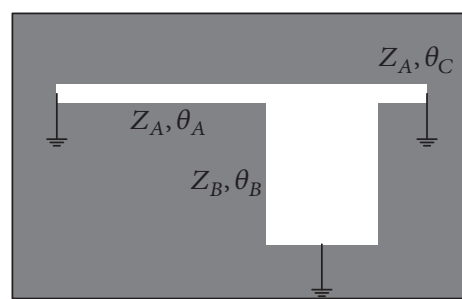

(b)

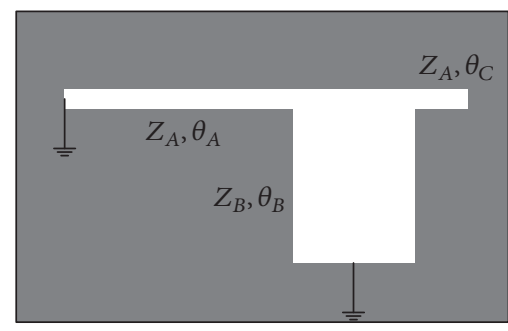

(c)

FIGURE 1: (a) Slotline MMR and its equivalent circuits (b) odd-mode and (c) even-mode.

studied, indicating the notch band can be fully controlled. Finally, a prototype filter is fabricated to verify the predicted dual-wideband performance in experiment.

\section{Design Approach for Proposed Filter}

2.1. Dual-Stub-Loaded MMR. Two stubs are symmetrically loaded to slotline, which forms a dual-stub-loaded MMR, as shown in Figure 1(a). Because the proposed slotline MMR is a symmetrical structure, even-odd theory can be applied to analyze its resonant characteristics. Figures $1(\mathrm{~b})$ and $1(\mathrm{c})$ give equivalent circuits of the slotline MMR.

Under odd-mode excitation, the symmetrical plane can seem as short-circuited, and its resonant condition can be derived as

$$
\begin{aligned}
& Z_{B} \tan \theta_{B} \tan \theta_{C}+Z_{B} \tan \theta_{B} \tan \theta_{A}+Z_{A} \tan \theta_{A} \tan \theta_{C} \\
& \quad=0,
\end{aligned}
$$

where $Z_{A}, Z_{B}$ and $\theta_{A}, \theta_{B}, \theta_{C}$ are the characteristic impedances and electrical lengths of the dual-stubs loaded MMR, respectively.

Under even-mode excitation, the symmetrical plane can seem as open-circuited, and its resonant condition can be summarized as

$$
Z_{A} \tan \theta_{A}+Z_{B} \tan \theta_{B}=Z_{B} \tan \theta_{A} \tan \theta_{B} \tan \theta_{C} .
$$

Resonant modes of the resonator can be controlled and allocated according to the requirements by changing the parameters of the resonator.

To have a clear knowledge of slotline resonator, resonant characteristics of the dual-stub-loaded slotline resonator are performed by invoking the 3D EM simulator. Resonant modes of slotline resonator against $S, L_{1}$, and $L_{2}$ are plotted in Figure 2, where $f_{1}, f_{2}$, and $f_{3}$ indicate the first, second, and third resonant modes of resonator, respectively. When $S$ increases from $0.2 \mathrm{~mm}$ to $2.2 \mathrm{~mm}, f_{3}$ decreases from $9.6 \mathrm{GHz}$ to $8.2 \mathrm{GHz}$, while $f_{1}$ and $f_{2}$ shift slightly. When $L_{1}$ increases from $23 \mathrm{~mm}$ to $25 \mathrm{~mm}$, both $f_{1}$ and $f_{2}$, together with $f_{3}$, decrease steadily. When $L_{2}$ increases from $1 \mathrm{~mm}$ to $6 \mathrm{~mm}, f_{2}$ drops from $8.2 \mathrm{GHz}$ to $6.5 \mathrm{GHz}$ and $f_{3}$ drops from $13.5 \mathrm{GHz}$ to $8 \mathrm{GHz}$, while $f_{1}$ keeps unchanged. Though this method, three resonant modes of the resonator can be designed intuitively and well set in the UWB passband.

2.2. Ultra-Wideband BPF. Layout of a proposed UWB BPF is depicted in Figure 3, which is constructed by a slotline resonator and two microstrip feedlines. On the bottom layer, a dual-stub-loaded slotline resonator is formed firstly, where two identical stubs are symmetrically loaded to a uniform slotline resonator. Figure 4 illustrates the frequency responses of the slotline UWB BPF with different lengths of feed line $\left(L_{4}\right)$ under all the other sizes fixed. When the slotline resonator is fed under weak coupling case with $L_{4}=$ $4.8 \mathrm{~mm}$, three resonant modes with peak $S_{21}$-magnitudes are observed at about $4.08,6.41$, and $9.5 \mathrm{GHz}$, respectively. As $L_{4}$ increases to $10 \mathrm{~mm}$, the $S_{21}$-magnitude realizes an almost flat frequency response over a UWB passband. After its sizes are slightly adjusted, an UWB frequency response is satisfactorily realized. Under the use of this hybrid microstrip/slotline structure, the desired strong coupling between feed lines and MMR can be easily achieved by properly selecting the relative position between them.

2.3. Realization of Notch Band. Considering the fact that the above-achieved UWB passband range may interfere with the existing wireless systems such as wireless local area network (WLAN), a notch band may be highly demanded in various practical applications. For this purpose, a microstrip dualmode triangular loop resonator is formed on the top layer of a dielectric substrate and loaded to the slotline MMR. 

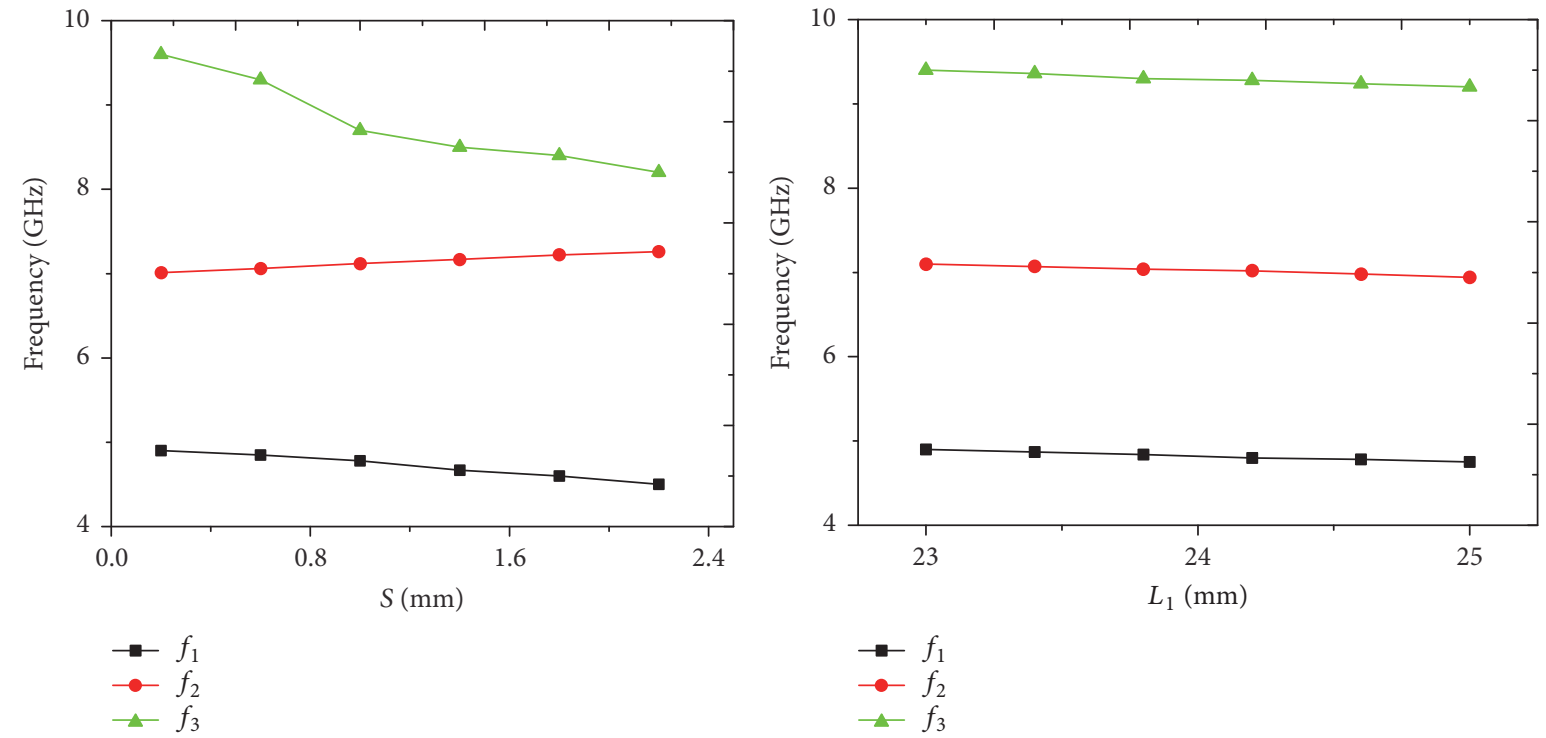

(a)

(b)

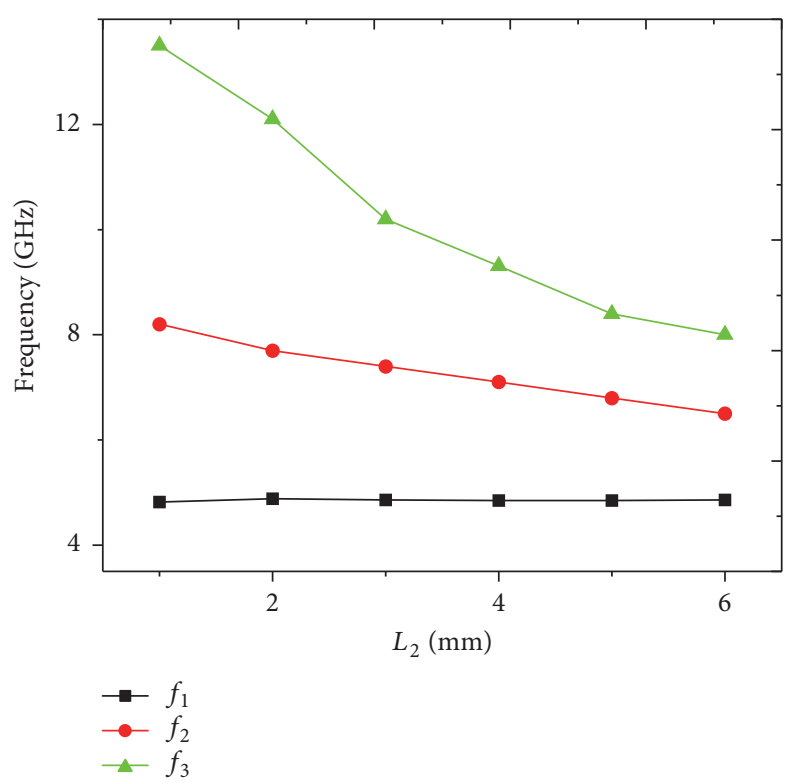

(c)

FIGURE 2: Resonant modes of slotline resonator with fixed $W_{1}=2.0 \mathrm{~mm}, W_{2}=0.3 \mathrm{~mm}$, and varied (a) $S$ ( $L_{1}=23 \mathrm{~mm}, L_{2}=3 \mathrm{~mm}$ ), (b) $L_{1}$ $\left(S=0.6 \mathrm{~mm}, L_{2}=3 \mathrm{~mm}\right)$, and (c) $L_{2}\left(S=0.6 \mathrm{~mm}, L_{1}=23 \mathrm{~mm}\right)$.

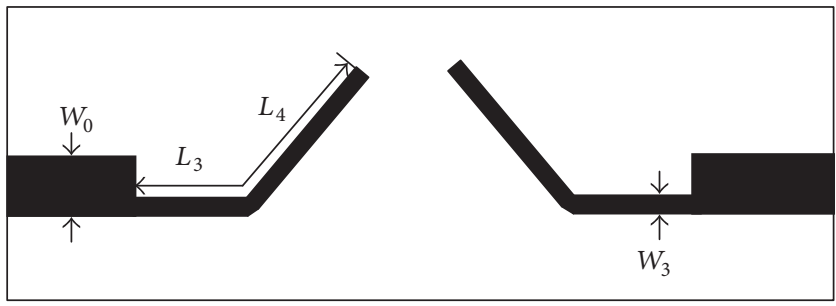

(a)

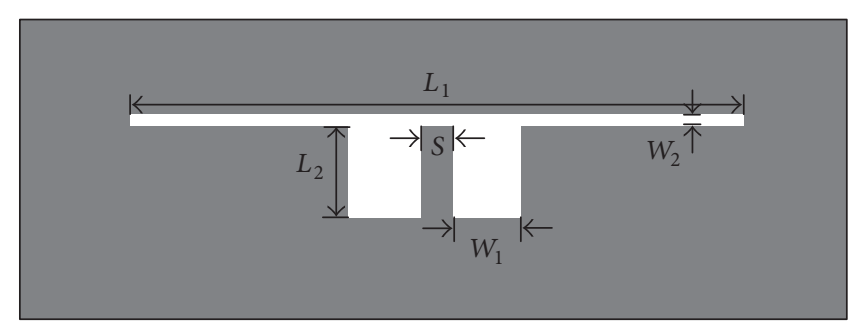

(b)

FIGURE 3: Schematic of the UWB filter. (a) Top layer and (b) bottom layer. 


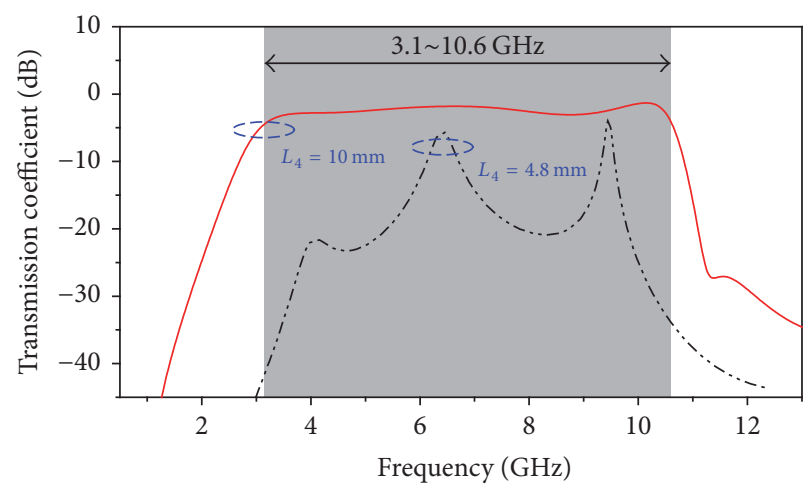

FIGURE 4: Frequency responses of transmission coefficient of the proposed wideband BPF with different feeding line lengths $\left(L_{4}\right)$.

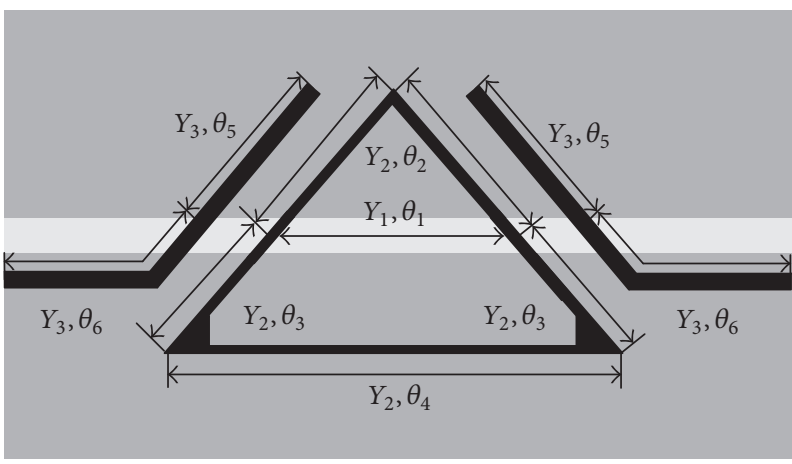

(a)

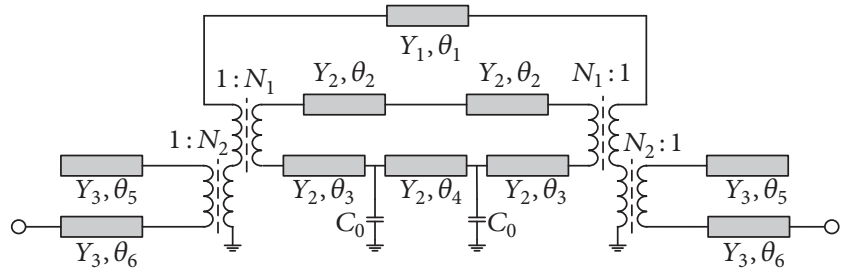

(b)

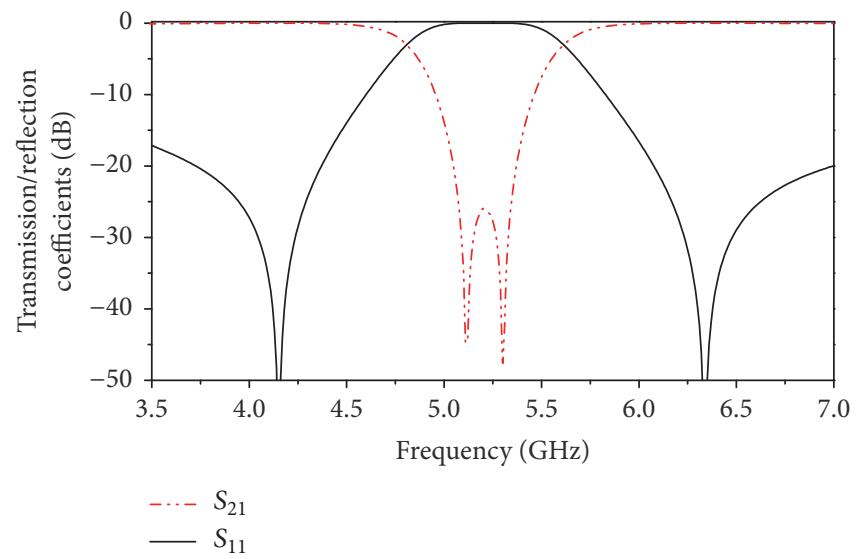

(c)

Figure 5: A microstrip triangular loop resonator loaded with backside slotline portion. (a) Diagram, (b) equivalent circuit model, and (c) simulated results.

Figure 5 depicts the geometry, equivalent circuit model, and simulated frequency response of a slotline loaded with back sided microstrip triangular loop resonator, respectively. Figure 5(a) shows a simplified circuit geometry of the structure, where the white portion indicates the slotline and the black ones are microstrip feed lines and a dual-mode triangular loop resonator with perturbations. Its equivalent circuit model is given in Figure 5(b). Coupling between dualmode resonator and source/load can be intuitively neglected because its value is quite small. Figure 5(c) plots the simulated result derived from the equivalent circuit model, where the solid and dashed lines indicate the simulated reflection and transmission coefficients, respectively. Two transmission zeros in the notch band are created by the resonant modes of the microstrip resonator.

Next, two small patches are symmetrically added as the perturbation element to the lower angles of the triangular loop resonator. These perturbations can accomplish the further separation of the two degenerate modes, creating the dual-mode behavior of the resonator. Resonant modes of the triangular loop resonator are coupled to the slotline, providing a bypass for the adjacent signal of its resonance, 


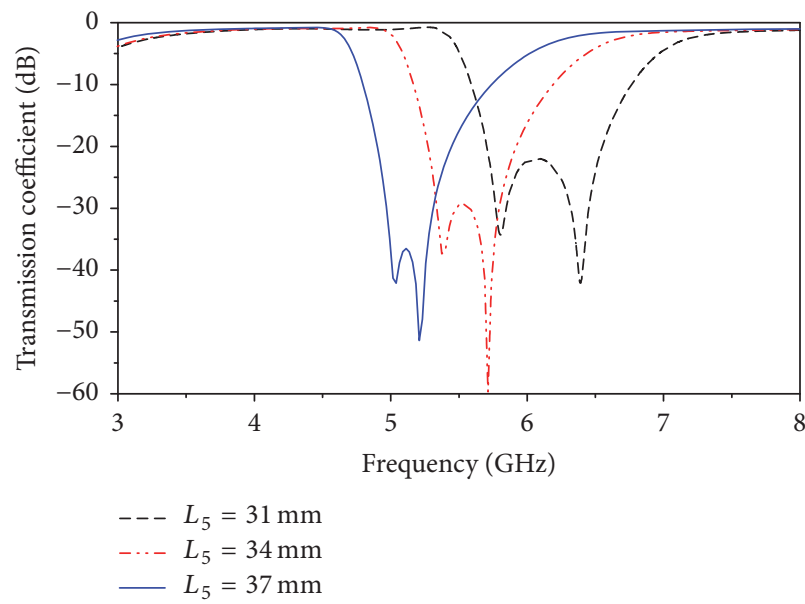

(a)

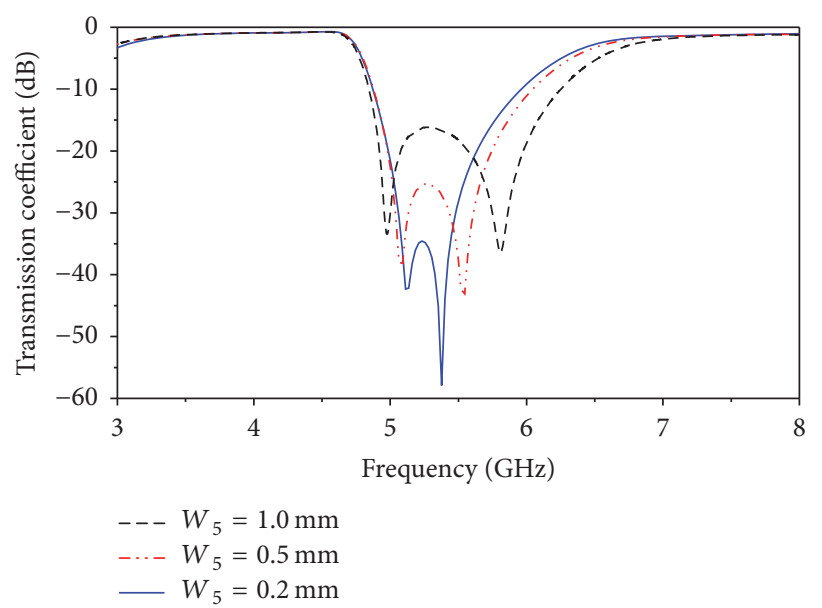

(b)

FIGURE 6: Frequency-dependent transmission coefficient of the proposed dual-mode triangular loop resonator loaded slotline against (a) $L_{5}$ and (b) $W_{5}$.

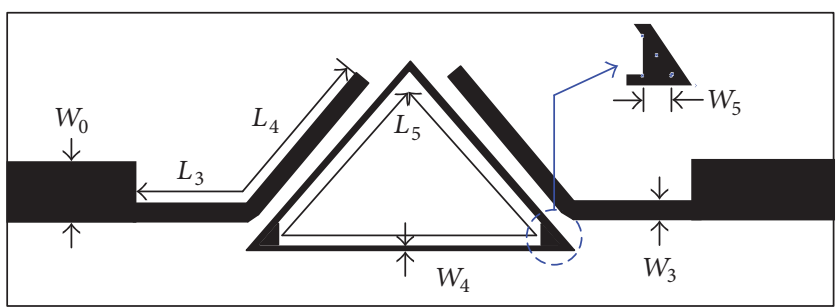

(a)

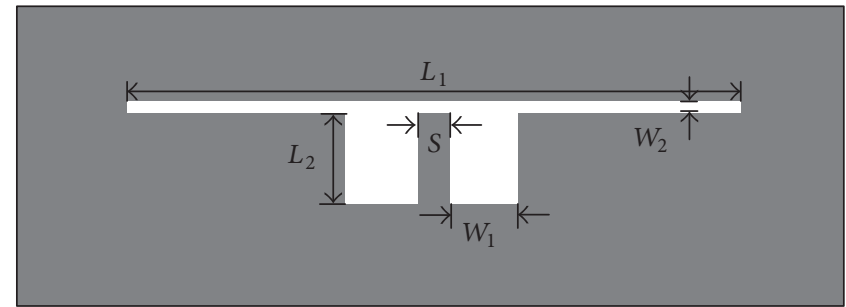

(b)

FIGURE 7: Schematic of the proposed filter. (a) Top layer and (b) bottom layer.

and a notch band is thus created. Figure 6(a) shows the transmission characteristics of the resonator versus $L_{5}$, that is, the perimeter of a triangular loop resonator. As $L_{5}$ increases from 31 to $37 \mathrm{~mm}$, the central frequency of notch band falls off from 6.25 to $5.39 \mathrm{GHz}$ and its absolute bandwidth decreases from 1.49 to $1.37 \mathrm{GHz}$. Obviously, the perimeter of triangular loop resonator can directly determine the position of the notch band. Figure 6(b) illustrates the influence on the frequency response from varied $W_{5}$ and width of two patches. As $W_{5}$ increases from 0.2 to $1.0 \mathrm{~mm}$, the notch bandwidth goes up from 1.52 to $1.79 \mathrm{GHz}$. These exhibited characteristics can be used to determine the central frequency and bandwidth of the created notch band; thus, the notch band of the UWB BPF can be fully controlled.

\section{Filter Implementation and Results}

Based on the filter structure and analysis approach described above, a UWB BPF with a controllable notch band is designed and fabricated on a substrate with a dielectric constant of $\varepsilon_{r}=3.5$, loss tangent of 0.0018 , and thickness of $h=0.8 \mathrm{~mm}$. The layout of proposed UWB BPF with a notch band is depicted in Figure 7. As mentioned above, a dual-stub-loaded slotline resonator is etched on the ground plane, and on the top layer, two folded microstrip feedlines and a microstrip triangular loop resonator are constructed. All the dimensions of the filter shown in Figure 7 are as follows: $W_{0}=1.8 \mathrm{~mm}$, $L_{1}=23.0 \mathrm{~mm}, W_{1}=2.0 \mathrm{~mm}, L_{2}=3.0 \mathrm{~mm}, W_{2}=0.3 \mathrm{~mm}$, $L_{3}=2.0 \mathrm{~mm}, W_{3}=0.8 \mathrm{~mm}, L_{4}=11.5 \mathrm{~mm}, W_{4}=0.6 \mathrm{~mm}$, $L_{5}=36 \mathrm{~mm}, W_{5}=0.3 \mathrm{~mm}$, and $S=0.6 \mathrm{~mm}$.

Simulated and measured transmission and reflection coefficients of the constructed filter are plotted in Figure 8. Simulated results show that the $3-\mathrm{dB}$ passband of the filter covers the ranges of $2.83-4.78 \mathrm{GHz}$ and $6.29-10.33 \mathrm{GHz}$, respectively, while measured ones show that the $3-\mathrm{dB}$ passband cover the ranges of $2.49-4.91 \mathrm{GHz}$ and $6.29-9.2 \mathrm{GHz}$. Measured minimum insertion losses of the first and second passbands are $1.1 \mathrm{~dB}$ and $1.5 \mathrm{~dB}$, respectively. Measured maximum return losses in the first and second passbands are $13.2 \mathrm{~dB}$ and $13.5 \mathrm{~dB}$, respectively. Simulated and measured maximum insertion loss in the notch band is $25 \mathrm{~dB}$ and $35 \mathrm{~dB}$, respectively. In general, the measured results agree well with the simulated results except the loss in the high frequency band that may be caused by the dielectric loss and fabrication tolerance. Meanwhile, simulated and measured results indicate that the group delay within the passbands is varied within $0.3 \sim 0.7 \mathrm{~ns}$. The photographs of the fabricated filter are shown in Figure 9, and its overall size is about $28 \mathrm{~mm} \times 25 \mathrm{~mm}$. 


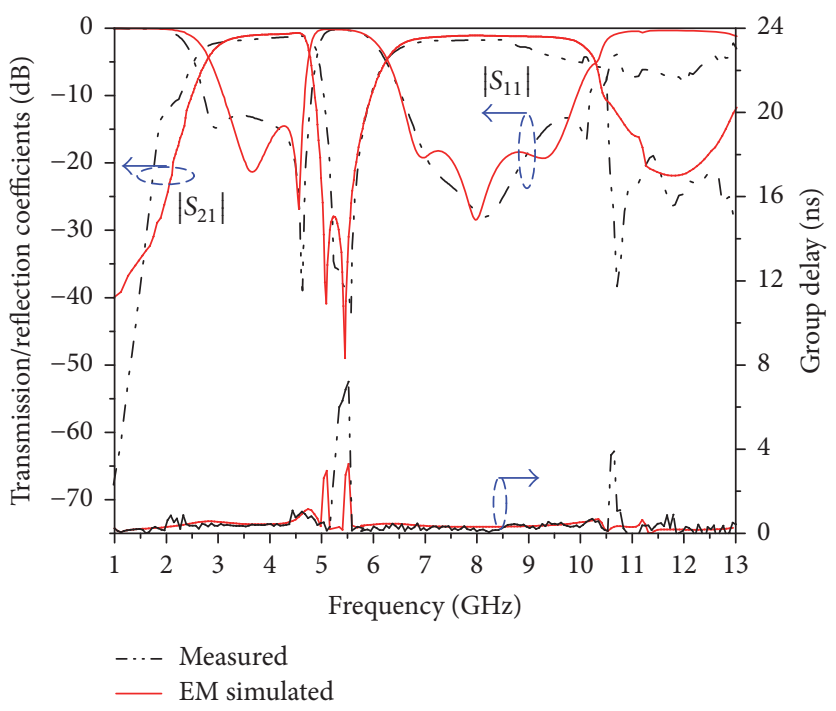

FIGURE 8: Simulated and measured frequency responses of the designed filter.

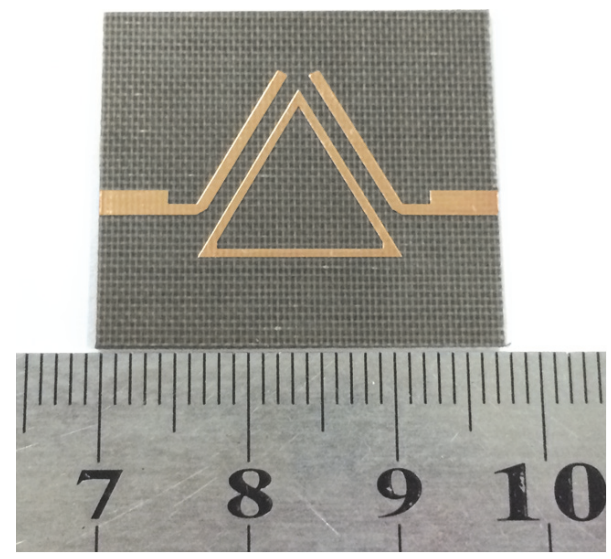

(a)

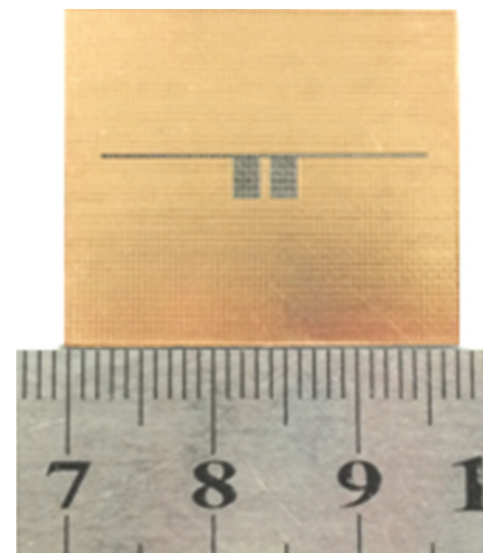

(b)

Figure 9: Photograph of the fabricated filter. (a) Top view and (b) bottom view.

TABLE 1: Comparisons between referenced works and our work.

\begin{tabular}{lcccc}
\hline $\begin{array}{l}\text { Ref. } \\
\text { number }(\mathrm{GHz}) / \mathrm{FBW}(\%)\end{array}$ & $\begin{array}{c}\text { Notch band } \\
(\mathrm{GHz}) /\left|S_{21}\right|(\mathrm{dB})\end{array}$ & $\begin{array}{c}\text { In-band } \\
\text { return loss } \\
(\mathrm{dB})\end{array}$ & $\begin{array}{c}\text { Circuit } \\
\text { size }\left(\lambda_{0}^{2}\right)\end{array}$ \\
\hline$[8]$ & $\begin{array}{c}3.65 / 63, \\
5.8 / 69\end{array}$ & $5.22 / 20$ & $>14 />12$ & 0.309 \\
& $3.96 / 59$, & $5.47 / 25$ & $>12 />11$ & 0.272 \\
{$[10]$} & $8.31 / 60$ & $5.3 / 37$, & & \\
& $4.4 / 32$, & $5.4 / 35$ & & 0.187 \\
{$[12]$} & $8.2 / 65$ & $5.1 / 39$, & & \\
This & $3.8 / 52$, & $5.5 / 45$ & & 0.181 \\
work & $8.31 / 49$ & & & \\
\hline
\end{tabular}

The comparison with other reported UWB BPFs is shown in Table 1, which depicts that the proposed filter has excellent notch band characteristics with compact size.

\section{Conclusion}

In this article, a novel UWB BPF with a controllable notch band using the hybrid microstrip/slotline structure is proposed. UWB BPF is at first designed by using the microstripfed stub-loaded slotline MMR. And then the notch band of 4.78-6.29 GHz is achieved by loading a dual-mode microstrip triangular loop resonator to the slotline MMR. A prototype UWB BPF is finally fabricated and good agreement between simulated and measured results is gained over a wide frequency range.

\section{Conflicts of Interest}

The authors declare that they have no conflicts of interest.

\section{Acknowledgments}

This work is supported by National Science Foundation Committee of China (nos. 61161005 and 61461020), Jiangxi 
Provincial Cultivation Program for Academic and Technical Leaders of Major Subjects (20162BCB22018), and Natural Science Foundation of Jiangxi Province (20152ACB21007).

\section{References}

[1] L. Zhu, S. Sun, and W. Menzel, "Ultra-Wideband (UWB) bandpass filters using multiple-mode resonator," IEEE Microwave and Wireless Components Letters, vol. 15, no. 11, pp. 796-798, 2005.

[2] S. S. Gao, X. S. Yang, J. P. Wang, S. Q. Xiao, and B. Z. Wang, "Compact ultra-wideband (UWB) bandpass filter using modified stepped impedance resonator," Journal of Electromagnetic Waves \& Applications, vol. 22, no. 22, pp. 541-548, 2008.

[3] Z.-C. Hao and J.-S. Hong, "Ultra wideband bandpass filter using embedded stepped impedance resonators on multilayer liquid crystal polymer substrate," IEEE Microwave and Wireless Components Letters, vol. 18, no. 9, pp. 581-583, 2008.

[4] H.-W. Wu, Y.-W. Chen, and Y.-F. Chen, "New ultra-wideband (UWB) bandpass filter using triangle-ring multi-mode stubloaded resonator," Microelectronics Journal, vol. 43, no. 11, pp. 857-862, 2012.

[5] L. Zhu and H. Wang, "Ultra-wideband bandpass filter on aperture-backed microstrip line," Electronics Letters, vol. 41, no. 18, pp. 1015-1016, 2005.

[6] X. Shi, X. Xi, J. Liu, and H. Yang, "Novel ultra-wideband (UWB) bandpass filter using multiple-mode resonator," IEICE Electronics Express, vol. 13, no. 11, 2016.

[7] C.-P. Chen, Y. Takakura, H. Nihie, Z. Ma, and T. Anada, "Design of compact notched UWB filter using coupled external stepped-impedance resonator," in Proceedings of the Asia Pacific Microwave Conference, APMC 2009, pp. 945-948, IEEE MTT-S, Singapore, December 2009.

[8] R. Ghatak, P. Sarkar, R. K. Mishra, and D. R. Poddar, "A compact UWB bandpass filter with embedded SIR as band notch structure," IEEE Microwave and Wireless Components Letters, vol. 21, no. 5, pp. 261-263, 2011.

[9] H. Sun, C. Feng, Y. Huang et al., "Dual-band notch filter based on twist split ring resonators," International Journal of Antennas and Propagation, vol. 2014, Article ID 541264, 6 pages, 2014.

[10] G. Yang, R. Jin, C. Vittoria, V. G. Harris, and N. X. Sun, "Small ultra-wideband (UWB) bandpass filter with notched band," IEEE Microwave and Wireless Components Letters, vol. 18, no. 3, pp. 176-178, 2008.

[11] R. Uikey, R. S. Sangam, K. Prasadu, and R. S. Kshetrimayum, "Novel notched UWB filter using stepped impedance stub loaded microstrip resonator and spurlines," International Journal of Microwave Science and Technology, vol. 2015, Article ID 939521, 2015.

[12] P. Sarkar, B. V. K. Reddy, M. Pal, and R. Ghatak, "UWB bandpass filter with broad notch band and ultra-wide upper stopband," in Proceedings of the 2013 IEEE MTT-S International Microwave and RF Conference, IMaRC 2013, New Delhi, India, December 2013.

[13] J. Huang, Q. Chu, and C. Liu, "Compact uwb filter based on surface-coupled structure with dual notched bands," Progress In Electromagnetics Research, vol. 106, pp. 311-319, 2010.

[14] S. S. Karthikeyan and R. S. Kshetrimayum, "Notched UWB bandpass filter using complementary single split ring resonator," IEICE Electronics Express, vol. 7, no. 17, pp. 1290-1295, 2010. 


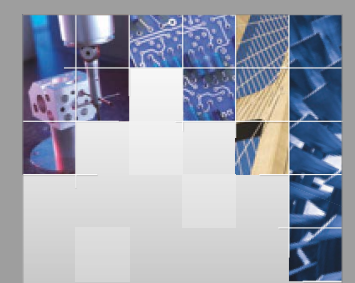

\section{Enfincering}
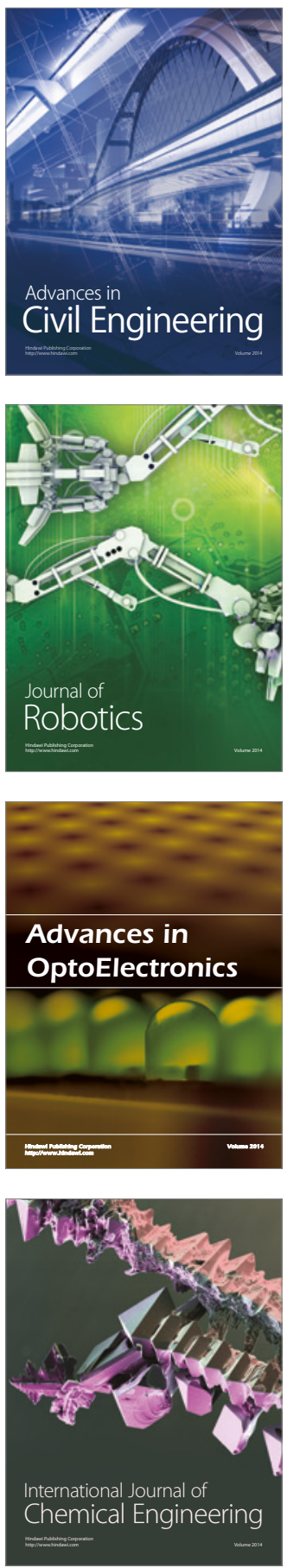

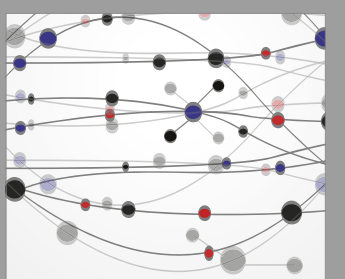

The Scientific World Journal

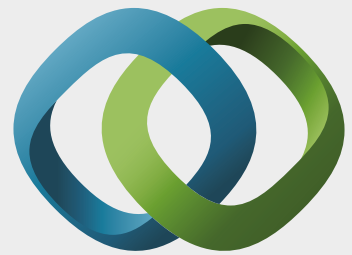

\section{Hindawi}

Submit your manuscripts at

https://www.hindawi.com
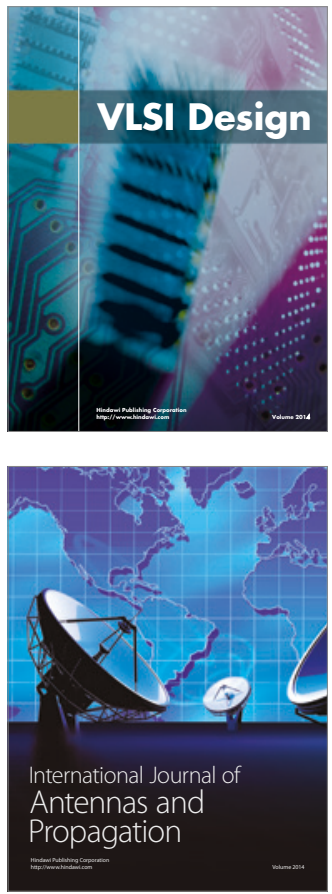

\section{Rotating}

Machinery
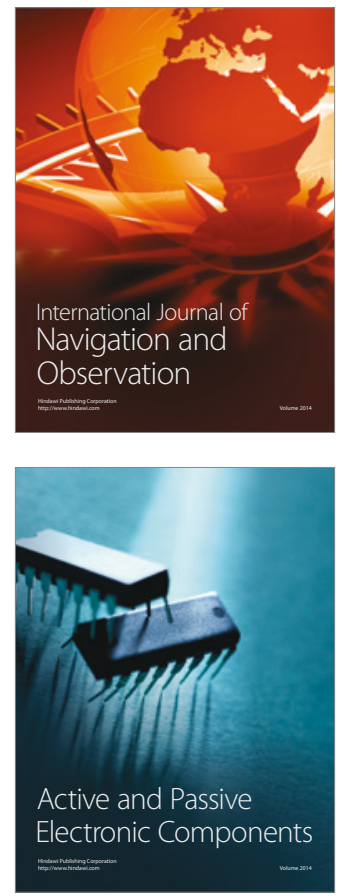
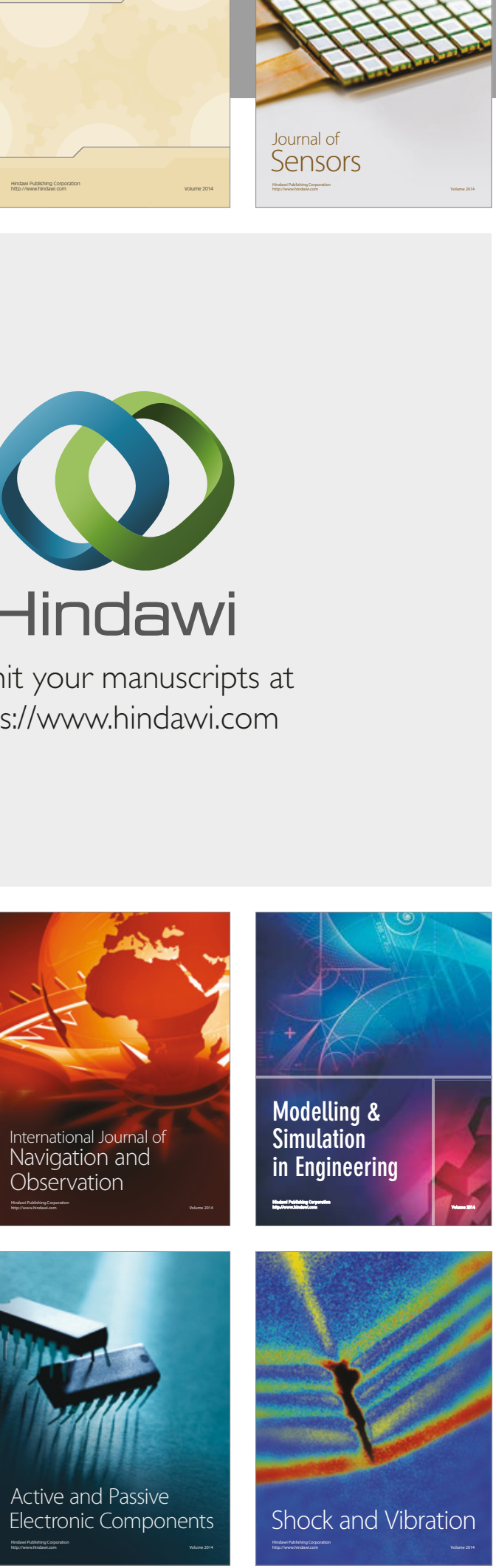
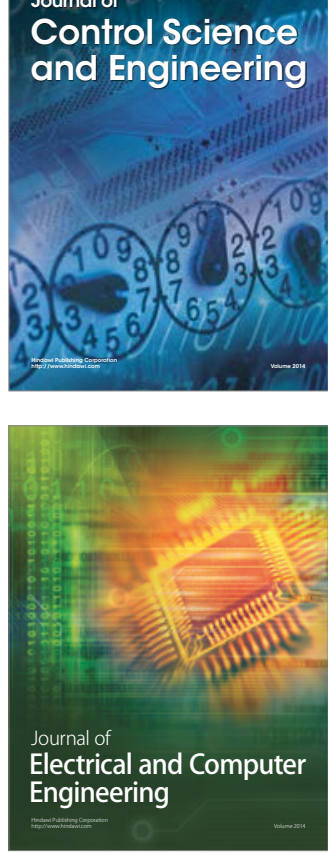

Distributed

Journal of

Control Science

and Engineering
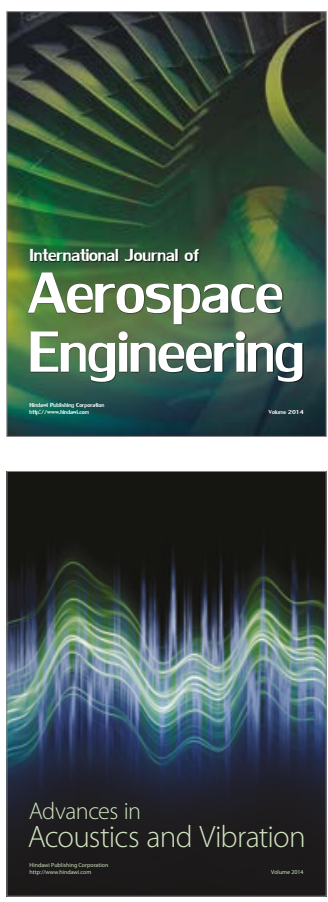

Sensor Networks 